\title{
FORMA E PAISAGEM URBANA DE LISBOA
}

\author{
URBAN FORM AND LANDSCAPE OF LISBON
}

\section{Vítor Oliveira*}

\section{RESUMO}

Este artigo descreve a aplicação da metodologia Morpho na análise da forma e paisagem urbana de Lisboa. Para além de uma avaliação morfológica da capital portuguesa, centrada nos principais elementos de forma urbana (ruas, parcelas e edifícios), desenvolve-se neste artigo uma apreciação do Plano Diretor Municipal de Lisboa de 2012 e do Plano de Urbanização do Alto do Lumiar de 1998, tendo em consideração a coerência interna das suas propostas, o papel dos objetivos e a relevância das propostas do plano para a capital do país. Palavras-chave: Morfologia urbana. Forma urbana. Metodologia Morpho. Lisboa.

\section{ABSTRACT}

This paper describes the application of the Morpho methodology in the analysis of the urban form and landscape of Lisbon. In addition to the morphological assessment of the Portuguese capital, focused on the main elements of urban form (streets, plots and buildings), this paper offers an appraisal of the so-called Plano Diretor Municipal de Lisboa prepared in 2012 and of the Plano de Urbanização do Alto do Lumiar completed in 1998, bearing in mind the internal coherence of the plan proposals, the role of the plan objectives and the relevance of the plan proposals for the capital of the country.

Keywords: Urban morphology. Urban form. Morpho Methodology. Lisbon.

\section{MORPHO: METODOLOGIA PARA ANALISAR A FORMA E A PAISAGEM URBANA}

Esta primeira seção dedicada à metodologia Morpho começa com a apresentação de um conjunto de princípios genéricos que informaram a sua concepção. $\bigcirc$ primeiro princípio é que a Morpho deve lidar exclusivamente com a dimensão física das cidades. Embora se reconheça que a forma e a estrutura das cidades são fortemente influenciadas por fatores sociais e econômicos, estes são refletidos pela Morpho de um modo indireto. Essa técnica centra-se, assim, nos contributos essenciais e específicos que o campo de conhecimento da morfologia urbana pode dar às cidades e sociedades contemporâneas. O segundo princípio é que a Morpho, como outras abordagens morfológicas, envolve a seleção de um conjunto reduzido de elementos físicos com o propósito de descrever e explicar a cidade em termos morfológicos: as ruas, as parcelas e os edifícios. Nada disso constitui uma novidade, sendo que um conjunto de outros exemplos, apoiado nessa simplificação da realidade, pode ser encontrado na literatura.

\footnotetext{
Licenciado em Arquitetura pela Faculdade de Arquitetura da Universidade do Porto (FAUP). Mestre em Planejamento e Projeto do Ambiente Urbano pela Faculdade de Engenharia da Universidade do Porto (FEUP) e pela FAUP. Doutor em Engenharia Civil pela FEUP. Professor auxiliar na Universidade Lusófona do Porto (ULP).

http://vitoroliveira.fe.up.pt/
} 
Um desses casos é o trabalho desenvolvido por Karl Kropf em torno do conceito de tecido urbano, fazendo convergir duas escolas de pensamento morfológico, a Escola Muratoriana e a Escola Conzeniana. (CATALDI; MAFFEI; VACCARO, 2002; WHITEHAND, 2007). Kropf (1996) afirma que o tecido urbano é um todo orgânico cuja forma pode ser descrita a vários níveis de resolução, cada um deles centrado em diferentes elementos da forma urbana: ruas e quarteirões (séries de parcelas); parcelas; edifícios; salas ou espaços; estruturas, como paredes ou telhados (incluindo detalhes da construção), e materiais. A space syntax (HILLIER, 1996; HILLIER; HANSON, 1984) fornece um conjunto de conceitos e métodos para avaliar um único elemento da forma urbana - o sistema de ruas -, utilizando um único critério de avaliação, a acessibilidade. Por sua vez, a place syntax (STAHLE et al., 2006) expande o enfoque exclusivo da abordagem sintática no sistema de ruas de uma cidade, incluindo também o sistema de parcelas.

O terceiro princípio considerado é que a Morpho deve avaliar quantitativamente a base morfológica de uma determinada área urbana, enquadrada por um conceito de urbanidade. Isso significa que a performance das formas urbanas dessa área será expressa por um grau de urbanidade, como parte de uma gradação contínua que vai do rural ao urbano. A utilização de um conceito de urbanidade para enquadrar a avaliação da forma urbana foi desenvolvida por autores como Duany (2002) e Marcus (2010), em termos operacionais, e por Lees (2010) e Holanda (2011) em termos estratégicos. Embora partilhe com essas propostas todo um conjunto de aspectos, a abordagem que se preconiza na proposta da Morpho aponta para um conceito de urbanidade mais específico. Urbanidade é uma construção com dimensões social e espacial. É algo que - ambiente construído oferece através dos principais elementos da forma urbana - o sistema de ruas, o sistema de parcelas e o sistema de edifícios. Um elevado grau de urbanidade significa (em relação a esses elementos) elevada acessibilidade, elevada densidade, grande diversidade e forte sentido de continuidade. $O$ conceito de urbanidade que aqui se sustenta também assume duas questões fundamentais: primeiro, a urbanidade resulta de um conjunto de contribuições planejadas e de uma série de contributos não planejados; segundo, a urbanidade é construção contínua, como o é, também, o próprio conhecimento.

Finalmente, a Morpho deve fornecer bases sólidas para investigações morfológicas integradas e para a prática de planejamento. Essa avaliação pode ser sincrônica e diacrônica, monitorizando a evolução da forma urbana ao longo do tempo. Pode, assim, centrar-se no presente e no passado das cidades. No entanto, a Morpho também pode centrar-se no futuro e avaliar o impacto morfológico de potenciais ações ou projetos sobre áreas urbanas.

A aplicação da Morpho inclui quatro fases fundamentais. A primeira fase compreende a reflexão sobre a adequação da técnica à área urbana em questão e ao tipo de estudo que se pretende desenvolver. Nesse âmbito, as questões a considerar incluem os objetivos do processo de avaliação, os critérios utilizados e a adequação dos dados disponíveis (cartográficos e estatísticos) para uma caracterização morfológica abrangente. Essa fase inicial pode ser lenta - por vezes, exigente - e conduzir a 
ajustes na própria técnica. A Morpho deve ser capaz de avaliar a forma urbana em relação a diferentes escalas - a rua, o bairro e a cidade -, permitindo a identificação das principais forças e fragilidades dessas formas urbanas e fornecendo orientações no sentido de minimizar as fragilidades.

A segunda fase corresponde à avaliação de sete critérios: a acessibilidade das ruas (semelhante ao critério utilizado pela space syntax), a densidade das parcelas, a época de construção dos edifícios (sublinhando a importância do fator tempo no processo de construção da cidade), a dimensão dos quarteirões (expressando a relação entre ruas e parcelas), o alinhamento dos edifícios (expressando a relação entre parcelas e edifícios), a relação entre altura dos edifícios e largura das ruas e, por fim, a função dos edifícios (tabela 1).

Tabela 1 Morpho: Critérios, Variáveis e Fontes

\begin{tabular}{|c|c|c|}
\hline Critério & Variável & Fonte \\
\hline C1. Acessibilidade das ruas & $\begin{array}{l}\text { Duas medidas sintáticas: } \\
\text { - Integração Global } \\
\text { - Integração Local }\end{array}$ & $\begin{array}{l}\text { Cartografia } \rightarrow \\
\text { Mapa axial }\end{array}$ \\
\hline C2. Densidade de parcelas & Número de parcelas por quarteirão & $\begin{array}{l}\text { Cartografia e } \\
\text { Informação estatística }\end{array}$ \\
\hline $\begin{array}{l}\text { C3. Época de construção dos } \\
\text { edifícios }\end{array}$ & $\begin{array}{l}\text { Número de edifícios anteriores a } \\
\text { x / número total de edifícios (por } \\
\text { quarteirão) }\end{array}$ & $\begin{array}{l}\text { Cartografia e } \\
\text { Informação estatística }\end{array}$ \\
\hline C4. Dimensão dos quarteirões & Área dos quarteirões & Cartografia \\
\hline C5. Alinhamento dos edifícios & $\begin{array}{l}\text { Comprimento do alinhamento } \\
\text { dominante (soma dos } \\
\text { comprimentos das fachadas dos } \\
\text { edifícios no mesmo alinhamento) / } \\
\text { Comprimento da frente edificada }\end{array}$ & Cartografia \\
\hline $\begin{array}{l}\text { C6. Relação entre altura dos } \\
\text { edifícios e largura das ruas }\end{array}$ & $\begin{array}{l}\text { Altura dos edifícios (média das } \\
\text { alturas dos dois lados da rua) / } \\
\text { Largura da rua }\end{array}$ & $\begin{array}{l}\text { Cartografia e Informação } \\
\text { estatística (ou Google Earth) }\end{array}$ \\
\hline C7. Função dos edifícios & $\begin{array}{l}N^{\circ} \text { de edifícios com mistura } \\
\text { de funções residencial e não } \\
\text { residencial / } N^{\circ} \text { total de edifícios } \\
\text { (por quarteirão) }\end{array}$ & $\begin{array}{l}\text { Cartografia e } \\
\text { Informação estatística }\end{array}$ \\
\hline
\end{tabular}

Tabela mostrando os sete critérios da metodologia Morpho, as variáveis e fontes de informação utilizadas para medi-los. Fonte: Vítor Oliveira, 2013

A avaliação de cada um desses critérios envolve a produção de um conjunto de tabelas e mapas, expressando diferentes performances e graus de urbanidade em diferentes partes da cidade. Em termos gráficos, é utilizada uma escala de cores que varia entre o vermelho e o azul-escuro. Os seis critérios avaliados com recurso a Sistemas de Informação Geográfica / SIG (o primeiro critério envolve, essencialmente, a análise de um mapa axial) adotam, normalmente, uma representação estruturada em seis classes, 
de acordo com a definição de intervalos naturais (natural breaks), expressa em quatro dos critérios através de um ordinary kriging, sublinhando, assim, as grandes diferenças territoriais e desvalorizando as exceções menos relevantes.

Depois de avaliar cada critério, os resultados são reunidos numa tabela, que constitui a base para um exercício de benchmarking. Cada resultado pode ser comparado com dois conjuntos de valores: um conjunto de valores local, baseado no contexto, e um conjunto de valores genérico. $\bigcirc$ primeiro conjunto pode fornecer referencial municipal para uma avaliação desenvolvida em relação a ruas, ou um referencial regional, em relação a cidades. $\bigcirc$ segundo conjunto deverá constituir uma construção contínua, informado por um processo de aprendizagem baseado em aplicações sucessivas da técnica numa variedade de ambientes e a diversas escalas.

A última fase desse processo constitui a proposta para a utilização dos resultados da avaliação. Um aspecto importante no desenvolvimento de um modelo ou de uma representação da cidade, é que não importa quão complexo ou baseado na evidência o modelo seja, porque será sempre apenas um modelo da cidade e não a própria cidade. Isso significa que a utilização da Morpho e dos seus resultados sempre deverá ser um processo crítico e reflexivo. É nossa firme convicção que essa técnica, se cuidadosamente aplicada, poderá ser usada por técnicos de autoridades locais, fornecendo um conjunto de informações de base para a prática de planejamento municipal e para a gestão urbanística.

\section{A CIDADE DE LISBOA}

Na segunda década deste novo milênio, em tempos de grande incerteza (nomeadamente econômica e financeira), a cidade de Lisboa enfrenta alguns desafios fundamentais. Por um lado, tem de lidar com uma série de problemas, que vêm do final do século $X X$, como a contínua redução da população residente, o aumento dos desequilíbrios urbanos e sociais, os reduzidos níveis de mobilidade e acessibilidade, a persistente degradação do ambiente construído e o inadequado sistema de tomada de decisão. Por outro lado, Lisboa tem de lidar com um conjunto de grandes projetos infraestruturais, como a ampliação do aeroporto ou o sistema viário à escala metropolitana. Além disso, é exigido à atividade de planejamento de Lisboa que forneça produtos, processos e resultados mais eficazes, quer à escala municipal quer à escala local.

\section{APLICAÇÃO DA METODOLOGIA MORPHO À CIDADE DE LISBOA}

Os parágrafos seguintes descrevem a aplicação da Morpho à cidade de Lisboa. Além de uma avaliação da cidade, desenvolve-se, nesta seção, uma apreciação do Plano Diretor Municipal (PDM) de 2012 e do Plano de Urbanização do Alto do Lumiar (PUAL) de 1998, tendo em consideração a coerência interna das suas propostas e o papel dos objetivos, e a relevância das propostas do plano para Lisboa. 


\subsection{ACESSIBILIDADE TOPOLÓGICA DAS RUAS}

Para a avaliação da acessibilidade topológica das ruas de Lisboa, recorreu-se à técnica da análise axial e utilizou-se o programa Depthmap. Após a construção do mapa axial da cidade, desenvolveu-se uma análise centrada em duas medidas sintáticas: a integração global e a integração local (tabelas 2 e 3). Nas figuras la e 1b, como nas seguintes, as cores mais quentes, próximas do vermelho, representam partes da cidade com valores mais elevados para cada critério em análise. As cores mais frias, até o azul-escuro, representam partes da cidade com valores mais reduzidos para cada um desses critérios.

À escala global a análise sintática revela que o núcleo mais integrado inclui um conjunto de eixos que vai desde a praça do Rossio, a sul (não incluindo, portanto, a Baixa Pombalina), até a avenida Brasil, a norte (compreendendo o bairro de Alvalade), lateralmente contido pelas avenidas da Liberdade e Almirante Reis respectivamente a poente e à nascente. Ao contrário, as partes mais segregadas da cidade (em azul-escuro na figura la) encontram-se na zona ocidental (Belém, São Francisco Xavier, Ajuda e Alcântara), numa parte da zona norte (entre a Charneca e Lumiar) e na zona oriental, particularmente em Chelas.

À escala local verifica-se que, em muitas das áreas segregadas encontradas anteriormente, emerge um conjunto de ruas com dinâmica de proximidade, que, de algum modo, consegue fornecer uma estrutura de suporte a esses territórios. Belém é um excelente exemplo do que se acaba de afirmar, com toda a sua malha de ruas radiais e circulares a sul da avenida do Restelo. A exceção mais relevante a essa tendência de estruturação local parece ser o caso de Chelas. De fato, um olhar sobre esse bairro, quer com um zoom municipal, quer com um zoom local, revela forte índice de segregação e forte separação em relação aos outros territórios que constituem a cidade de Lisboa.

Tabela 2 Acessibilidade Topológica das Ruas: Integração Global e Integração Local

\begin{tabular}{l|c|c}
\hline & Integração Global $[\mathrm{HH}]$ & Integração Local [HH] R3 \\
\hline Valor médio & 0,48 & 1,54 \\
\hline Valor máximo & 0,77 & 3,87 \\
\hline Valor mínimo & 0,25 & 0,33 \\
\hline Desvio padrão & 0,10 & 0,54 \\
\hline
\end{tabular}

Tabela mostrando os valores (médio, máximo e mínimo) de integração global e local do sistema de ruas de Lisboa. Fonte: Vítor Oliveira, 2013

\subsection{DENSIDADE DE PARCELAS}

Com este segundo critério procura-se perceber a diversidade de atores urbanos presentes na cidade de Lisboa, considerando essa diversidade como o "capital espacial" (MARCUS, 2010) desse território. Diante da ausência de plantas das parcelas da cidade 
em formato digital, utilizou-se como fonte de informação não o número de parcelas, mas o número de edifícios por quarteirão (informação do Instituto Nacional de Estatística - 2011). Como o número de parcelas livres em Lisboa não será muito elevado, pode admitir-se que esse procedimento não estará muito longe da realidade. Ainda assim, procurou-se identificar e corrigir eventuais incorreções, utilizando imagens de satélite.

A análise deste critério revela que é mais difícil estabelecer uma tendência gradativa do que no critério anterior (figura 1c). No entanto, e apesar de resultar num padrão menos expressivo, encontram-se, uma vez mais, as grandes 'manchas azuis', representativas de quarteirões com número reduzido de parcelas nas zonas ocidental, norte e oriental da cidade. Curiosamente, também se encontra um conjunto de 'manchas azuis' na zona do centro histórico, devido à presença de quarteirões com dimensão extremamente reduzida e que, portanto, têm potencial limite máximo não muito elevado.

As zonas com valores mais elevados, ou seja, com número maior de parcelas, estão localizadas na zona central do município (na área interior à $2^{a}$ circular, excluindo a baixa) e na zona de Campolide e Alcântara. É interessante verificar que se reafirma a dominância de valores relativamente baixos da cidade efetuando a ponderação desses dados pela área dos quarteirões. No entanto, as zonas com valores mais elevados se mantêm, sendo visível a atenuação do efeito acima descrito devido à área dos quarteirões.

Tabela 3 Densidade de Parcelas

\begin{tabular}{l|c}
\hline \multicolumn{2}{c}{ Número de parcelas por quarteirão } \\
\hline Valor médio & 15,90 \\
\hline Valor máximo & 136,00 \\
\hline Valor mínimo & 1,00 \\
\hline Desvio padrão & 14,57 \\
\hline
\end{tabular}

Tabela mostrando o número (médio, máximo e mínimo) de parcelas por quarteirão na cidade de Lisboa. Fonte: Vítor Oliveira, 2013.

\section{3 ÉPOCA DE CONSTRUÇÃO DOS EDIFÍCIOS}

O terceiro critério da Morpho é a época de construção dos edifícios. Esse critério foi analisado com recurso à informação proveniente do INE relativa à idade do edificado, sendo esta posteriormente importada e trabalhada em ambiente SIG, desagregada ao nível da subseção estatística. À semelhança de aplicações anteriores da Morpho, foi definido o ano de 1945 como fronteira entre os dois períodos temporais considerados.

Uma análise do mapa correspondente a esse critério (figura 2a e tabela 4) revela a existência de uma cidade dual. De fato, a imagem separa claramente a zona do centro histórico, centro e arco ribeirinho, marcada pela forte presença de patrimônio edificado de toda a área envolvente, onde o edificado de construção mais recente é claramente dominante. 


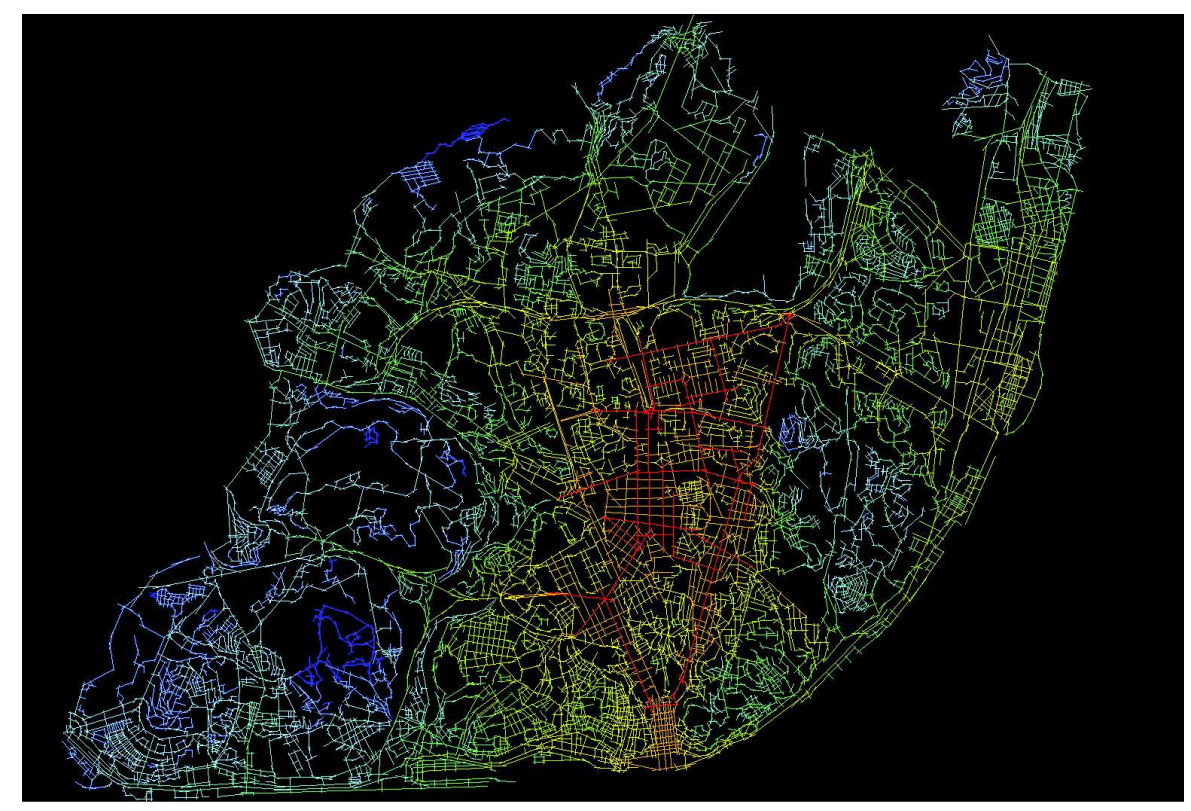

Figura la Integração global das ruas.

Mapa mostrando a integração global do sistema de ruas de Lisboa. As cores mais quentes, próximas do vermelho, representam partes da cidade com valores mais elevados de integração global. As cores mais frias, até o azul-escuro, representam partes da cidade com valores mais reduzidos.

Fonte: João Pinelo Silva e Teresa Heitor, 2013.

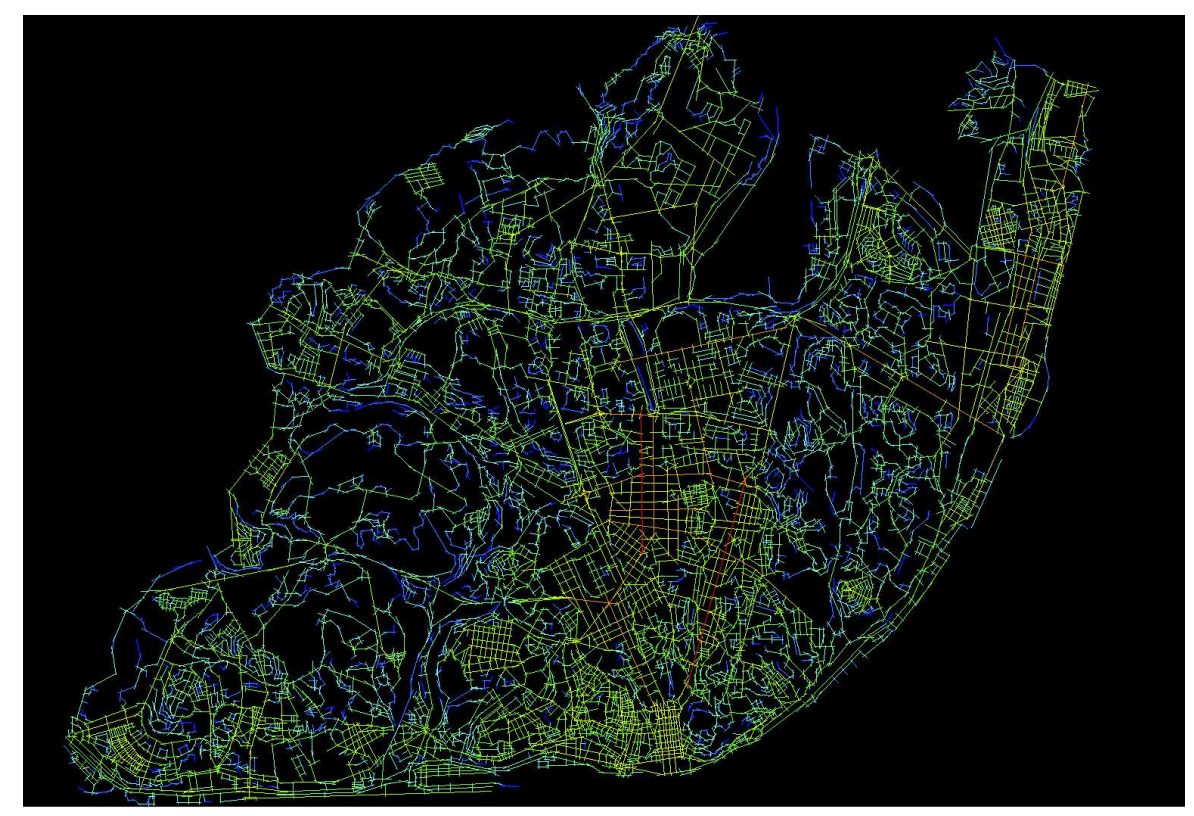

Figura $1 \mathrm{~b}$ Integração local das ruas.

Mapa mostrando a integração local do sistema de ruas de Lisboa. As cores mais quentes, próximas do vermelho, representam partes da cidade com valores mais elevados de integração global. As cores mais frias, até o azul-escuro, representam partes da cidade com valores mais reduzidos. Fonte: João Pinelo Silva e Teresa Heitor, 2013. 


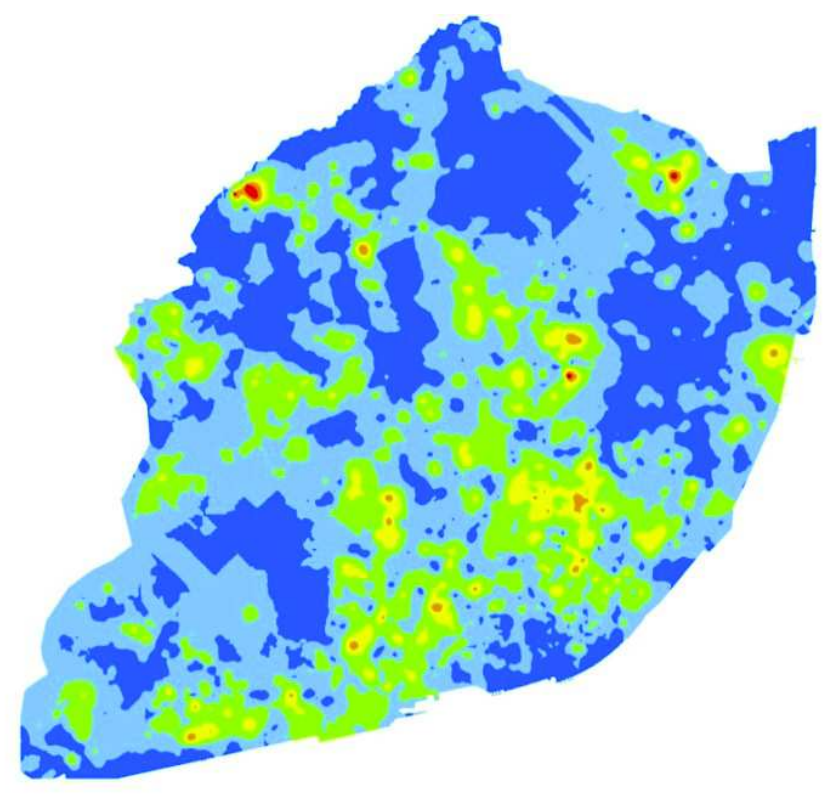

Figura 1c Densidade de parcelas.

Mapa mostrando a densidade de parcelas por quarteirão em Lisboa. As cores mais quentes, próximas do vermelho, representam partes da cidade com maior densidade de parcelas. As cores mais frias, até o azul-escuro, representam partes da cidade com menor densidade de parcelas.

Fonte: Vítor Oliveira, 2013.

A única exceção relevante a essa lógica parece ser o bairro da Encarnação. Apesar de os valores considerados estarem corretos - quer para o bairro da Encarnação, quer para a zona envolvente -, pressente-se no mapa produzido certo desajuste à realidade lisboeta, o que leva a considerar a necessidade de ajustar o modo de medição desse critério em futuras aplicações da Morpho. Apesar dessa consideração, não se considerou justificável questionar a inclusão do critério.

Tabela 4 Época de Construção dos Edifícios

\begin{tabular}{l|c}
\hline \multicolumn{2}{c}{ Índice de edifícios anteriores } \\
\hline Valor médio & 0,28 \\
\hline Valor máximo & 1,00 \\
\hline Valor mínimo & 0,00 \\
\hline Desvio padrão & 0,38 \\
\hline
\end{tabular}

Tabela mostrando o índice de edifícios (valores médio, máximo e mínimo) anteriores

a 1945, por quarteirão, existente na cidade de Lisboa.

Fonte: Instituto Nacional de Estatística, 2013.

\subsection{DIMENSÃO DOS QUARTEIRÕES}

A medição da dimensão dos quarteirões partiu de um conjunto de dados cartográficos referentes à planimetria dos quarteirões, sendo estes definidos pelo limite entre espaço 
público e espaço privado. Foram considerados não só os quarteirões construídos/edificados, mas também os quarteirões correspondentes a espaços de jardim e praças, assim como outros espaços exteriores de permanência. A variável de análise nesse caso foi a área dos quarteirões, expressa em $\mathrm{m}^{2}$. As opções de representação utilizadas (figura $2 \mathrm{~b}$ e tabela 5) foram o natural breaks com seis classes e o ordinary kriging.

À semelhança do que se concluiu para o critério 2, encontra-se aqui uma realidade relativamente heterogênea, onde, para além do progressivo aumento da dimensão dos quarteirões, à medida que se afasta da zona do centro histórico, é difícil identificar tendências com maior detalhe. Importa ainda referir que a dimensão média dos quarteirões de Lisboa, relativamente baixa, é muito próxima da dimensão média dos quarteirões da segunda cidade portuguesa, o Porto.

Tabela 5 Dimensão dos Quarteirões

\begin{tabular}{l|c}
\hline & Dimensão dos quarteirões $\left(\mathrm{m}^{2}\right)$ \\
\hline Valor médio & $21.851,00$ \\
\hline Valor máximo & $3.750 .123,00$ \\
\hline Valor mínimo & 4 \\
\hline Desvio padrão & $77.964,00$ \\
\hline
\end{tabular}

Tabela mostrando a dimensão (valores médio, máximo e mínimo) dos quarteirões da cidade de Lisboa.

Fonte: Vítor Oliveira, 2013.

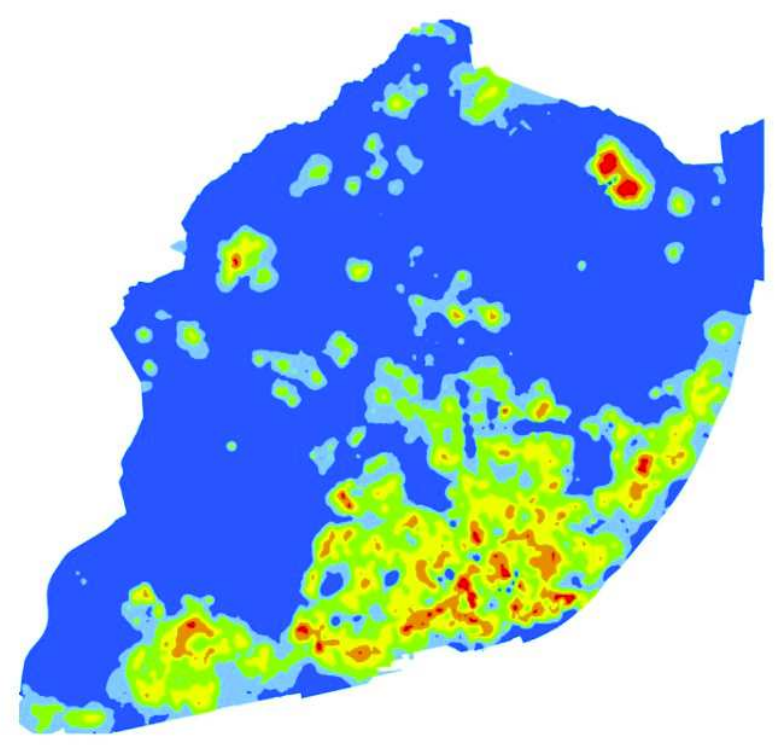

Figura 2a Época da construção dos edifícios. Mapa mostrando a época da construção dos edifícios de Lisboa. As cores mais quentes, próximas do vermelho, representam partes da cidade com maior número de edifícios construídos antes de 1945. As cores mais frias, até o azul-escuro, representam partes da cidade com menor número de edifícios construídos antes de 1945.

Fonte: Vítor Oliveira, 2013. 
Vítor Oliveira

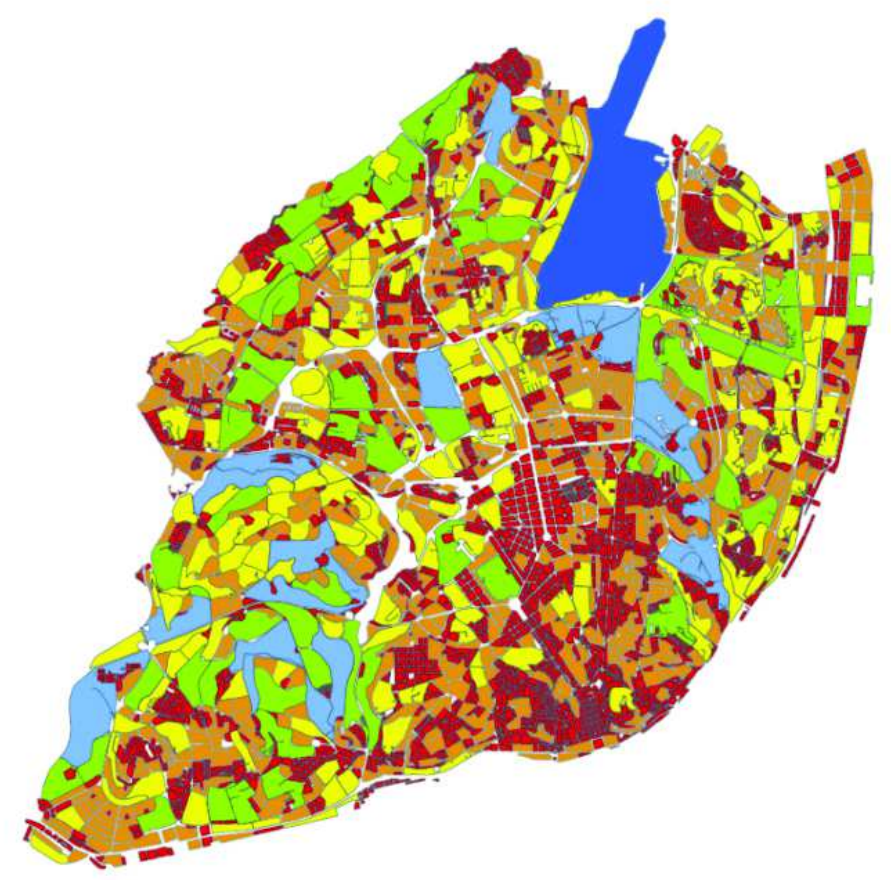

Figura $2 \mathrm{~b}$ Dimensão dos quarteirões. Mapa mostrando a dimensão dos quarteirões da cidade de Lisboa. As cores mais quentes, próximas do vermelho, representam partes da cidade com quarteirões de menor dimensão. As cores mais frias, até o azul-escuro, representam partes da cidade com quarteirões de maior dimensão. Fonte: Vítor Oliveira, 2013.

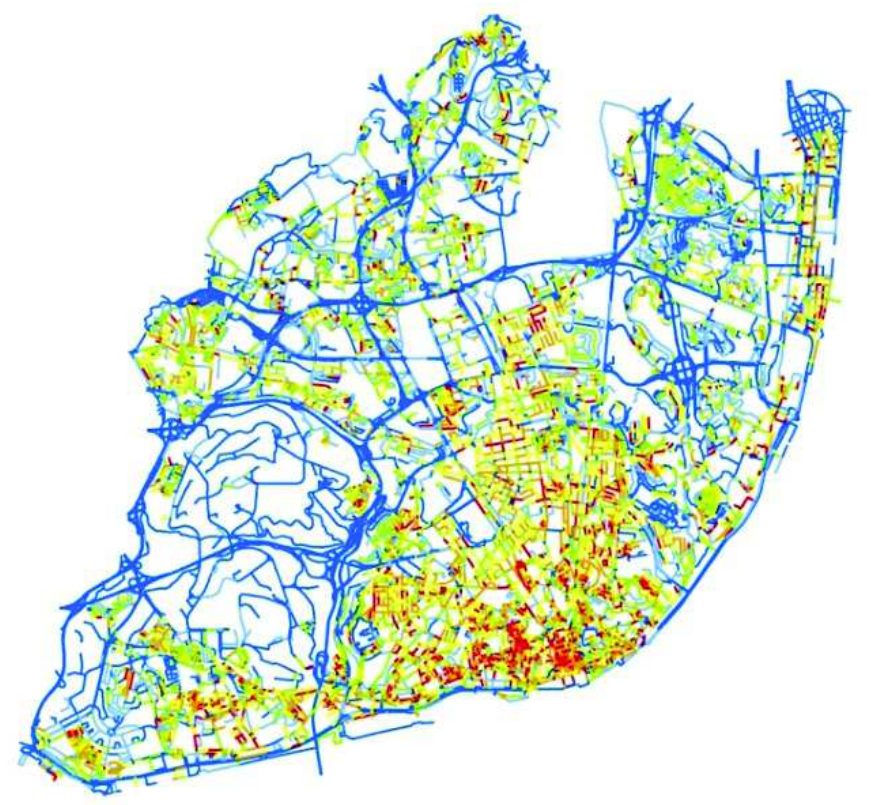

Figura 2c Alinhamento dos edifícios. Mapa mostrando a continuidade de alinhamento da frente edificada ao longo da rua na cidade de Lisboa. As cores mais quentes, próximas do vermelho, representam partes da cidade com maior continuidade de alinhamento. As cores mais frias, até o azul-escuro, representam partes da cidade com menor continuidade de alinhamento. Fonte: Vítor Oliveira, 2013. 


\subsection{ALINHAMENTO DOS EDIFÍCIOS}

O critério 5 da Morpho tem por objeto o alinhamento do edificado ao longo das ruas. A primeira fase desse processo, suportado por SIG, corresponde ao cálculo da distância de cada fachada ao respectivo eixo de via. Uma vez obtido esse conjunto de distâncias, é calculada a moda das mesmas, de modo a perceber qual o valor da distância correspondente ao alinhamento dominante. Por fim, é calculada a porcentagem de repetição desse valor relativamente ao total de edifícios, de forma a perceber a sua significância em face do todo. Esse procedimento foi efetuado para os dois lados de cada uma das ruas, sendo sempre adotado o valor com maior significância. Foi produzido um mapa em função da porcentagem de repetição. A forma de representação desse critério (figura 2 c e tabela 6 ) está associada às ruas e varia entre seis classes (natural breaks).

mapa produzido para a cidade de Lisboa mostra um critério onde é cada vez mais difícil perceber tendências territoriais dominantes. Apesar disso é possível perceber que os valores mais elevados (maior porcentagem de repetição) ocorrem no centro da cidade, começando a decrescer nas zonas mais periféricas. É junto aos mais importantes eixos viários da cidade - nomeadamente a Circular Regional Interior de Lisboa (CRIL), a estrada Eixo Norte-Sul, a alameda Linhas de Torres e as avenidas João XXI, Calouste Gulbenkian e Marechal Craveiro Lopes - que se verifica uma relação mais tênue. Em Lisboa o valor médio desse critério não é muito elevado, correspondendo à certa dispersão do edificado, existindo menor coesão em termos de continuidade espacial do território.

Tabela 6 Alinhamento dos Edifícios

\begin{tabular}{l|c}
\hline \multicolumn{2}{c}{ Índice de alinhamento dos edifícios } \\
\hline Valor médio & 0,39 \\
\hline Valor máximo & 1,00 \\
\hline Valor mínimo & 0,00 \\
\hline Desvio padrão & 0,33 \\
\hline
\end{tabular}

Tabela mostrando o índice (valores médio, máximo e mínimo) de alinhamento dos edifícios da cidade de Lisboa. Fonte: Vítor Oliveira, 2013.

\subsection{RELAÇÃO ENTRE ALTURA DOS EDIFÍCIOS E LARGURA DE RUA}

O critério 6 da Morpho avalia a relação entre a altura do edificado e a largura da rua (figura $3 a$ e tabela 7). Também a sua aplicação a Lisboa foi auxiliada pela utilização de SIG, envolvendo a utilização de informação vetorial relativa à rede viária, ao edificado e às subseções estatísticas. A análise partiu da altura dos edifícios em relação à subseção. 
O mapa gerado evidencia uma relação entre a altura dos edifícios e a largura das ruas que assume valores mais elevados na zona mais central da cidade (baixa) e noutros locais, como o Lumiar, Benfica e Belém. De modo geral, esse índice é razoavelmente elevado, sendo que a média dos valores se aproxima do valor 1 (um). Os pequenos núcleos onde essa relação é mais forte correspondem ao bairro da Encarnação e de Santa Catarina, ao Castelo e, mais distante do centro, ao bairro de Santa Maria dos Olivais e São João de Brito.

Na situação oposta, verifica-se a existência de algumas zonas cujos valores traduzem uma relação mais frágil entre altura de edifícios e largura de ruas. Naturalmente, as zonas que envolvem a Monsanto, o aeroporto e a faixa marginal junto ao rio se inserem nessa tendência.

Tabela 7 Relação entre Altura de Edifícios e Largura de Rua

\begin{tabular}{l|c}
\hline & $\begin{array}{c}\text { Índice de relação entre altura de } \\
\text { edifícios e largura de rua }\end{array}$ \\
\hline Valor médio & 0,88 \\
\hline Valor máximo & 3,75 \\
\hline Valor mínimo & 0,00 \\
\hline Desvio padrão & 0,81 \\
\hline
\end{tabular}

Tabela mostrando o índice (valores médio, máximo e mínimo) de relação entre altura de edifícios e largura de rua da cidade de Lisboa.

Fonte: Instituto Nacional de Estatística, 2013.

\subsection{FUNÇÃO DOS EDIFÍCIOS}

À semelhança dos critérios 2 e 3, também o critério 7, que analisa a função dos edifícios, foi construído utilizando como escala espacial a subseção estatística (figura 3b e tabela 8). Com base nessa informação foi constituído um índice que permite obter uma ideia da mistura de usos no território. $O$ referido índice assenta no quociente da soma dos 'edifícios principalmente residenciais' e dos 'edifícios principalmente não residenciais' pelo total de edifícios. O mapa criado representa o índice da mistura de usos na cidade de Lisboa em seis 'intervalos naturais'.

Lisboa tem porcentagem considerável de áreas monofuncionais ('exclusivamente residenciais' ou 'exclusivamente não residenciais'), como aliás se comprova pela média do índice utilizado (ligeiramente superior a 20\%). Nas áreas onde se verifica maior diversidade de usos não existe, no entanto, uma forte continuidade, mas sim uma distribuição de zonas monofuncionais intercaladas com núcleos de usos mistos (exceto a zona mais central). Essas áreas correspondem às subseções no interior da linha de comboio que liga Sete Rios a Entrecampos, onde é visível maior mistura de usos. Na situação oposta, encontram-se as zonas no quadrante Sudoeste da cidade, na zona Nordeste, e a Sudeste, apresentando forte carácter monofuncional (neste caso, residencial). 


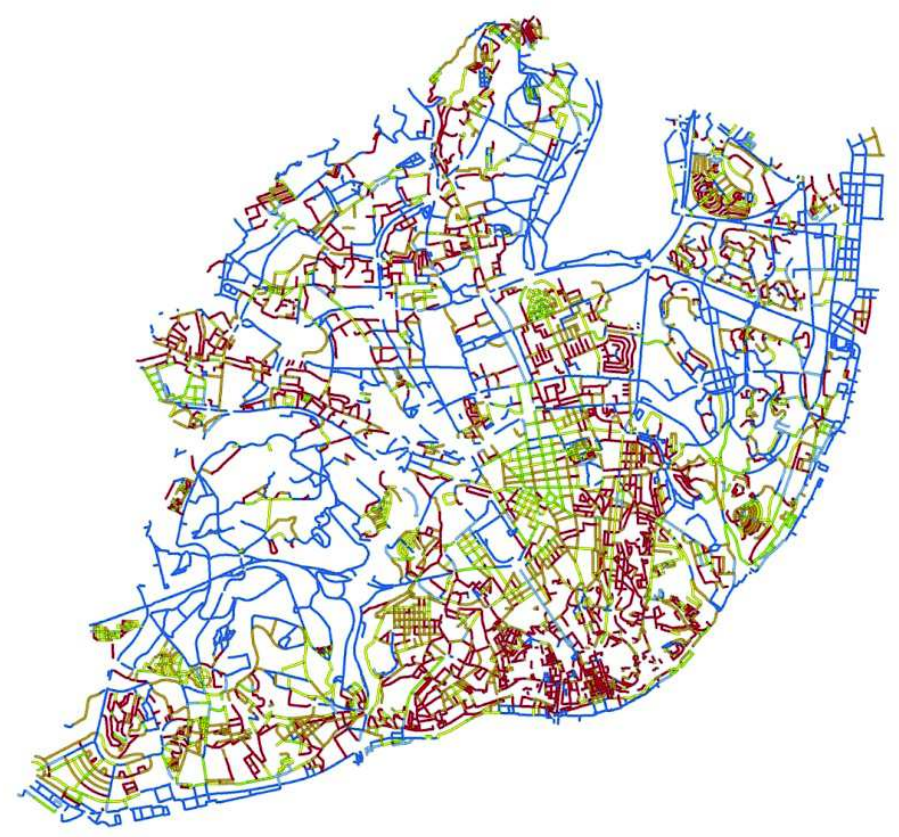

Figura 3a Relação entre altura de edifícios e largura de rua.

Mapa mostrando a relação entre altura de edifícios e largura de rua na cidade de Lisboa. As cores mais quentes, próximas do vermelho, representam partes da cidade com ruas com perfil mais vertical (encerrado). As cores mais frias, até o azul-escuro, representam partes da cidade com ruas com um perfil mais horizontal (aberto).

Fonte: Vítor Oliveira, 2013.

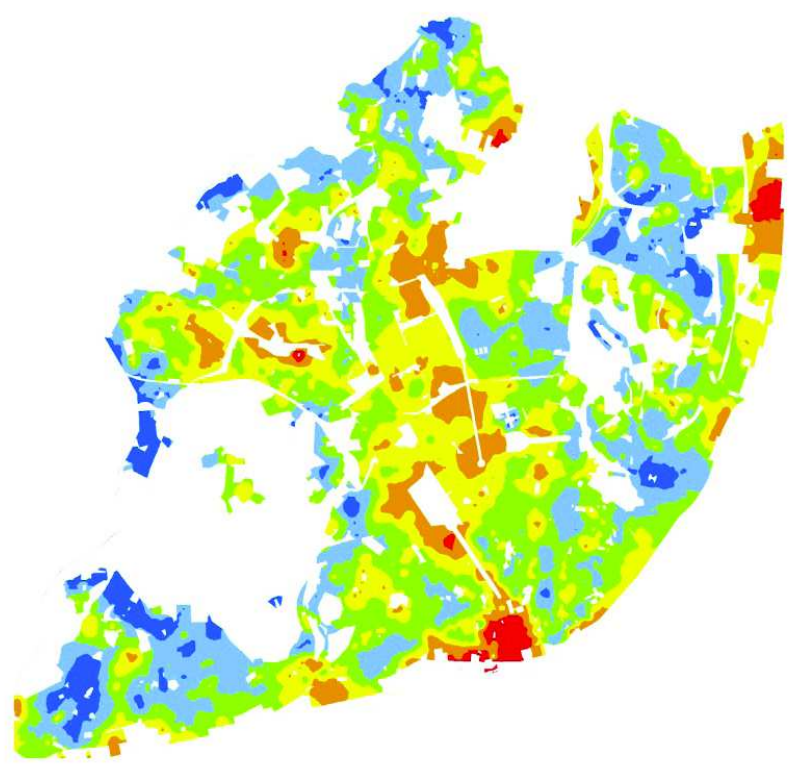

Figura 3b Função dos edifícios.

Mapa mostrando o índice da mistura de usos na cidade de Lisboa. As cores mais quentes, próximas do vermelho, representam a dominância de usos não residenciais. As cores mais frias, até o azul-escuro, representam a dominância de usos residenciais. As cores intermédias (amarelo e verde) representam uma maior mistura de usos.

Fonte: Vítor Oliveira, 2013. 
Tabela 8 Função dos Edifícios

\begin{tabular}{l|c}
\hline & $\begin{array}{c}\text { Relação entre o } \mathrm{n}^{\circ} \text { de edifícios com função } \\
\text { residencial e o } \mathrm{n}^{\circ} \text { total de edifícios }\end{array}$ \\
\hline Valor médio & 0,22 \\
\hline Valor máximo & 1,00 \\
\hline Valor mínimo & 0,00 \\
\hline Desvio padrão & 0,31 \\
\hline
\end{tabular}

Tabela mostrando, para cada parte da cidade de Lisboa, a relação entre o número de edifícios com função residencial e o número total de edifícios.

Fonte: Instituto Nacional de Estatística, 2013.

\subsection{SÍNTESE}

A aplicação da Morpho à cidade de Lisboa revelou um conjunto de aspectos fundamentais sobre a sua base morfológica. Em termos gerais, é possível dizer que essa base morfológica se caracteriza por certo equilíbrio. A exceção mais relevante em face dessa apreciação positiva prende-se com o sistema de ruas da cidade. De fato, os valores de integração global e local (particularmente o primeiro) para a cidade de Lisboa estão abaixo dos valores para a cidade europeia média. (HILLIER, 2002). Outro aspecto mais frágil evidenciado por meio da análise morfológica é a época de construção dos edifícios, que, no caso de Lisboa, dá origem a ambientes urbanos claramente distintos - a uma cidade dual.

Sobre as diferentes partes que constituem o território municipal, as maiores fragilidades correspondem a cinco territórios distintos (figuras 4a e 4b): i) Chelas, com sistema de ruas claramente segregado, sem articulação forte com o sistema de ruas da cidade e sem capacidade de estruturação local, dada a natureza muito fechada de cada uma das partes que compõem esse bairro Lisboeta; ii) Lumiar, com sistema de ruas que também não consegue participar do sistema de ruas da cidade, mas, ao contrário do território anterior, tem capacidade de estruturação local; iii) Carnide, com um conjunto de malhas muito diferente entre si e sem elemento unificador; iv) São Domingos de Benfica, com elevadas concentrações de áreas monofuncionais marcadas pelo atravessamento de grandes eixos viários; v) Olivais, território predominantemente residencial, onde é possível encontrar relação muito fraca entre ruas e edifícios - ao contrário, as partes do território municipal que apresentaram base morfológica mais sólida e, portanto, maior grau de urbanidade, encontram-se genericamente no centro histórico e no território suportado pelas avenidas Novas e Almirante Reis.

\section{APLICAÇÃO AO PLANO DIRETOR MUNICIPAL DE LISBOA DE 2012}

A aplicação da Morpho ao PDM de Lisboa partiu do pressuposto, reforçado pela abordagem de planejamento baseada na performance, de que os objetivos devem as- 

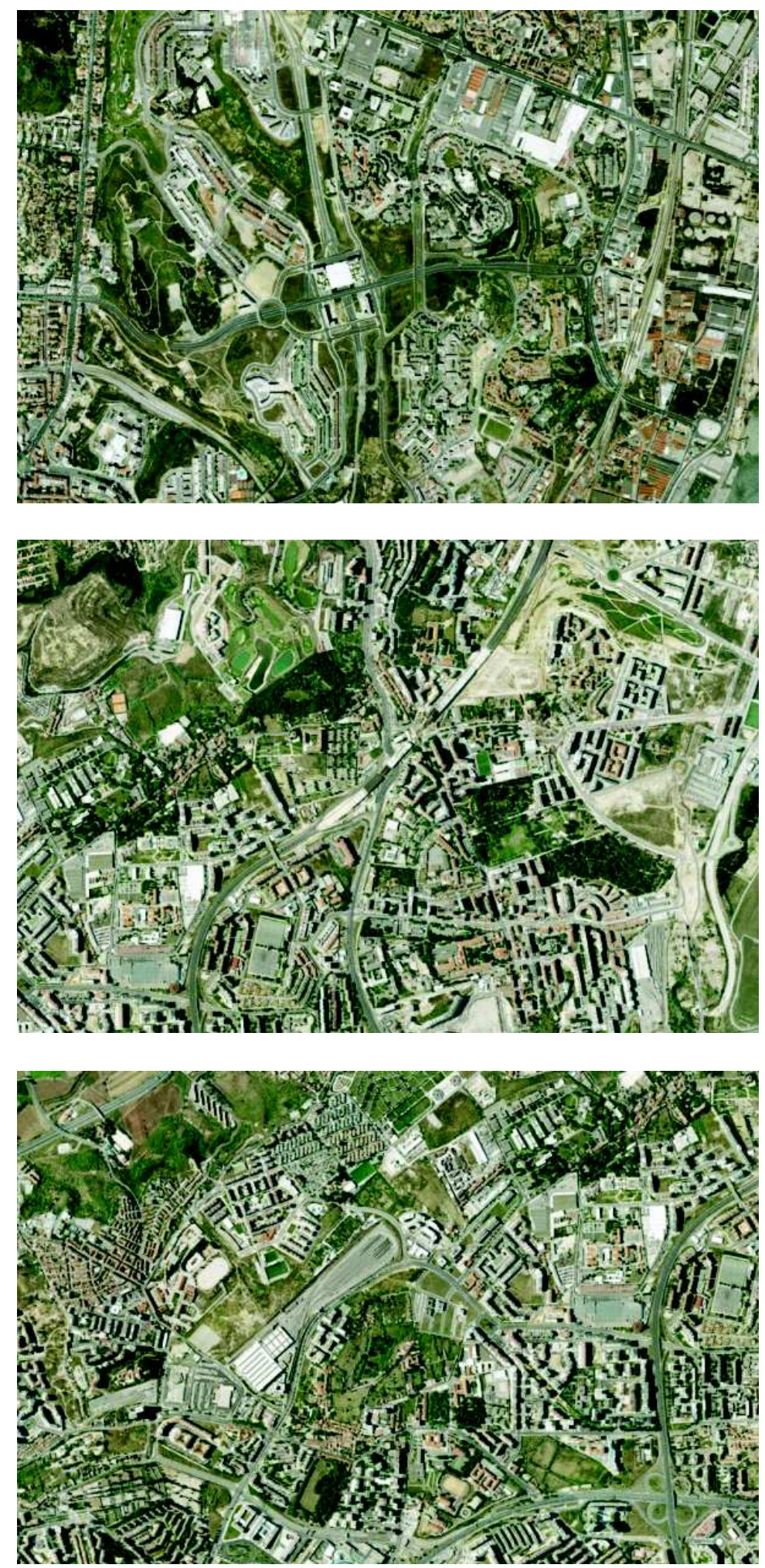

Figura 4a Chelas, Lumiar, Carnide.

Fotografias áreas mostrando algumas das partes do território municipal com maior fragilidade em relação à forma urbana.

Fonte: Google Earth, 2013. 

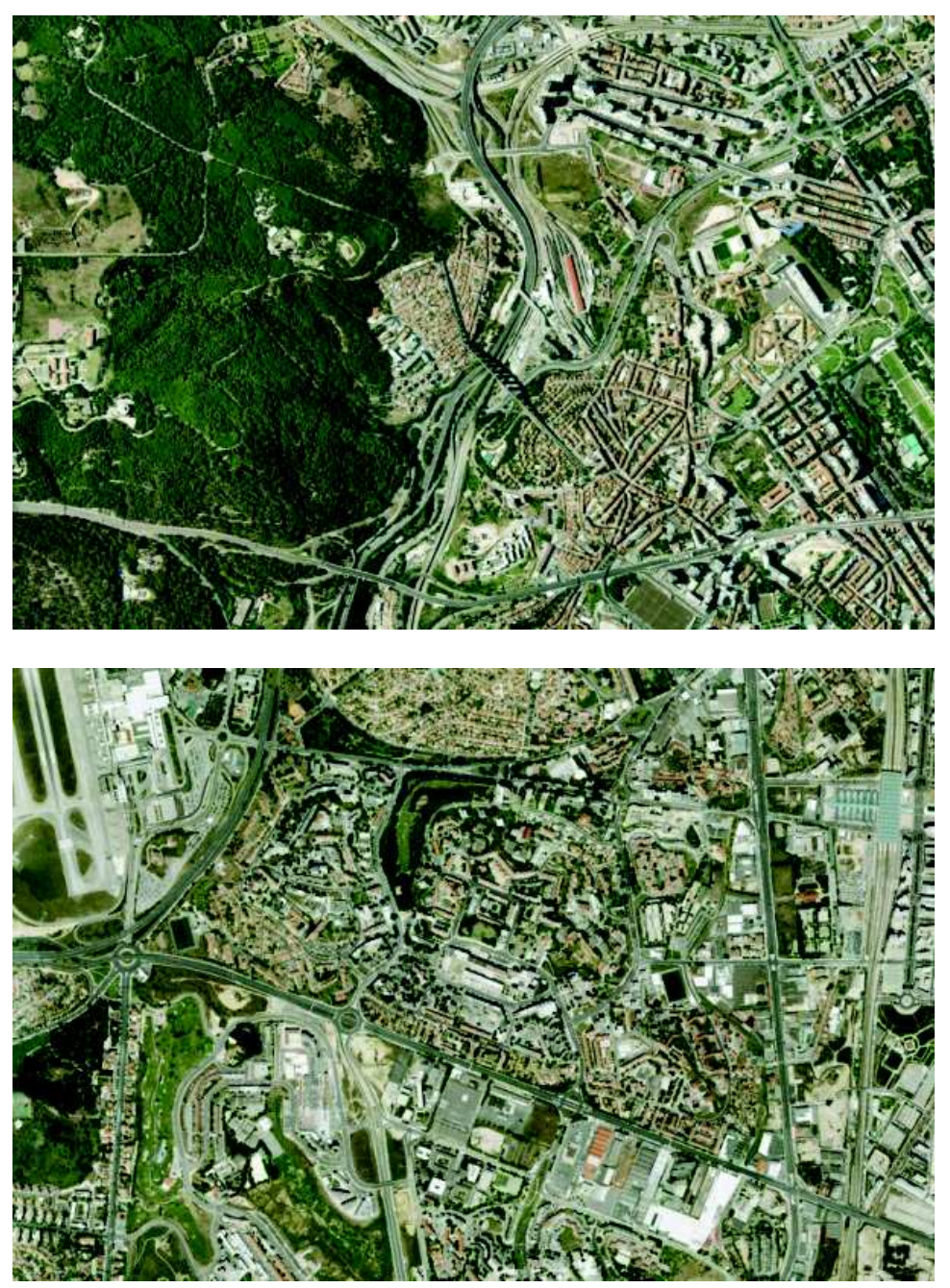

Figura 4b São Domingos de Benfica, Campolide, Olivais.

Fotografias áreas mostrando algumas das partes do território municipal com maior fragilidade em relação à forma urbana.

Fonte: Google Earth, 2013.

sumir papel cada vez mais central no plano e que as diferentes partes que compõem o plano devem contribuir de forma mais evidente para a concretização desses objetivos. Assim, procurou-se perceber como a Morpho poderia contribuir para a concretização de um ou mais objetivos do PDM.

O contributo mais evidente da Morpho será, porventura, para a concretização do Objetivo 2 - promover a reabilitação e a regeneração urbana. Segundo o PDM, a prossecução desse objetivo passa por alargar o conceito de área histórica a toda a cidade consolidada como forma de defesa e valorização dos seus patrimônios histórico, cultural e paisagístico. A abordagem de planejamento baseada na performance também sustenta que deve ser possível medir, ao longo da implementação do plano, o grau de concretização dos objetivos (ou o afastamento em relação a esses, para eventuais alterações). 
Nesse sentido, assumiu-se que a promoção da reabilitação e da regeneração urbana na capital portuguesa passaria por um reforço da qualidade da base morfológica da cidade. Assumiu-se, ainda, que a progressiva concretização desse objetivo poderia ser medida comparando os valores obtidos na análise morfológica da cidade com os valores obtidos na análise morfológica de cada proposta de planejamento (plano ou projeto). Dos cinco territórios com maior deficit de urbanidade, identificados anteriormente, selecionou-se a área do Lumiar para testar essa abordagem, avaliando o impacto das propostas de planejamento para essa área na cidade tomada como um todo (figura 5a).

Uma análise das propostas do PDM para o Lumiar revelou que diante da natureza e do nível de detalhe dessas mesmas propostas só era possível avaliar dois dos sete critérios morfológicos da Morpho: a acessibilidade das ruas e a dimensão dos quarteirões. O plano diretor propõe cinco novas ruas para o Lumiar (figura 5b). A avaliação das propostas do PDM no que se refere à acessibilidade das ruas passou pelo redesenho do mapa axial da cidade, considerando esses cinco eixos viários. $\bigcirc$ cálculo da integração global e da integração local revelou que em ambos os casos a concretização das novas propostas do plano se traduziriam num aumento da integração média da cidade - de 0,20\% no primeiro caso e 0,19\% no caso da integração local. Apesar de esses valores parecerem relativamente baixos, importa sublinhar que se está a analisar o impacto na média da cidade e que, numa situação real, aquilo que interessaria verificar, no final dos dez anos de vigência do plano, era o impacto de todas as intervenções produzidas ao longo desse período de tempo.

Segue uma apreciação do critério 4, a dimensão dos quarteirões. A abertura das cinco novas ruas introduz transformações em oito quarteirões. A comparação com os quarteirões resultantes permite afirmar que a contribuição dessa operação para a média da cidade é a redução de $0,6 \%$ na dimensão média do quarteirão lisboeta.

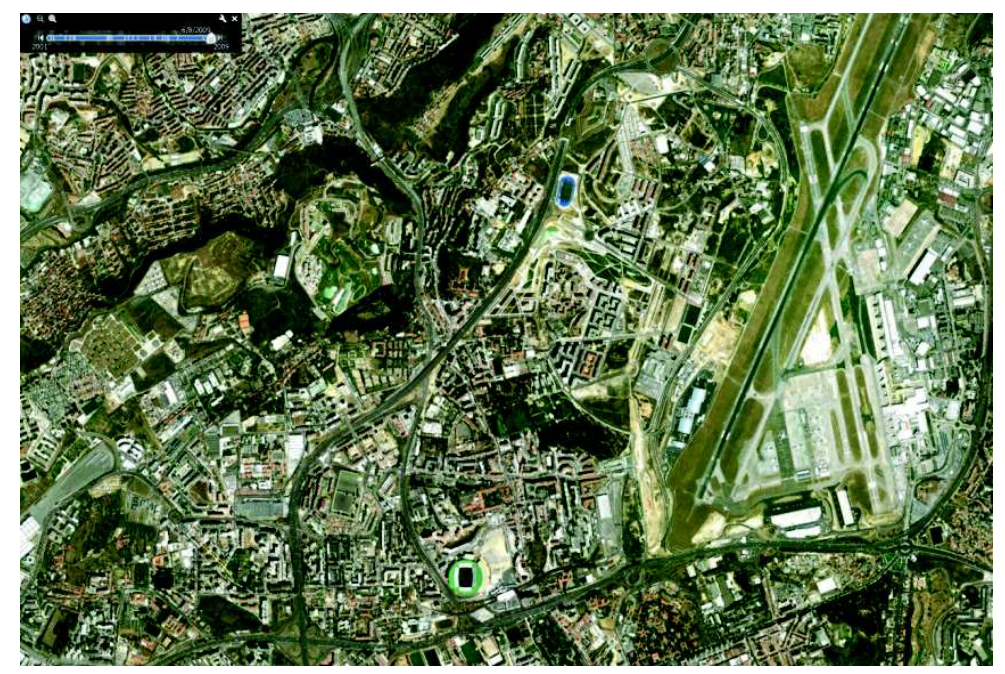

Figura 5a Área do Lumiar: situação existente.

Fotografia aérea mostrando a situação existente numa das partes do território municipal com maior fragilidade em relação à forma urbana, a área do Lumiar. Fonte: Google Earth, 2013. 


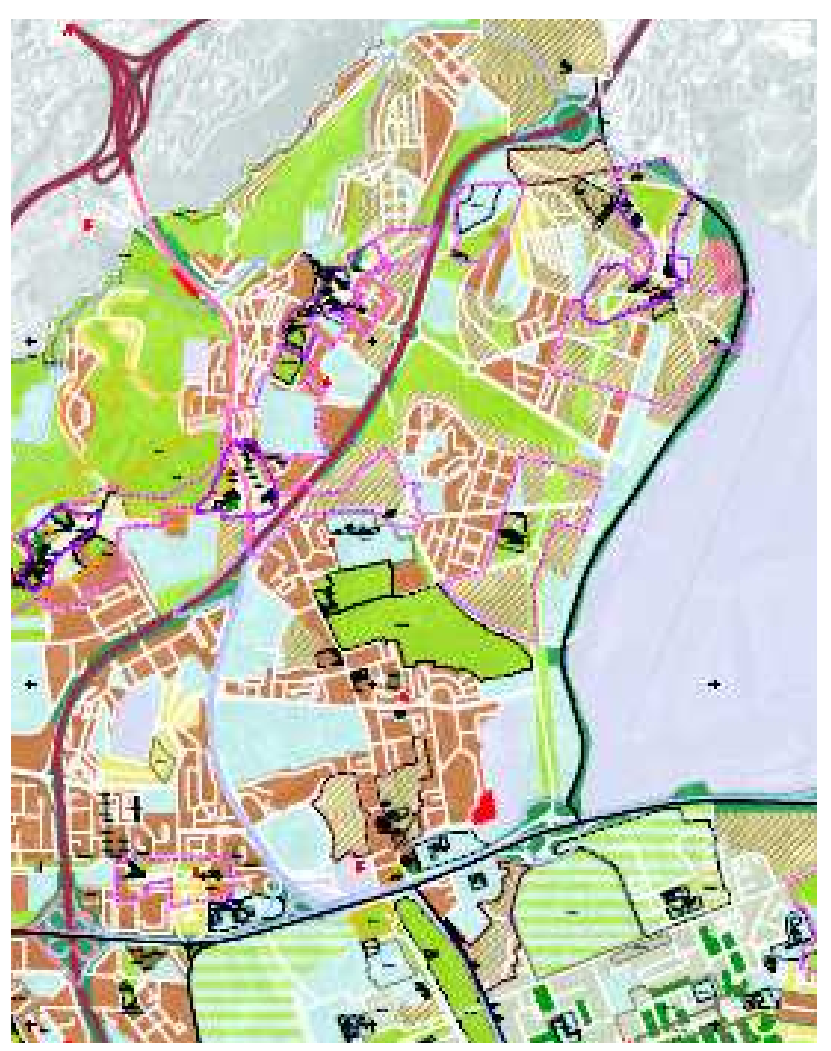

Figura 5b Área do Lumiar: Proposta do PDM.

Mapa mostrando as propostas do Plano Diretor Municipal para a área do Lumiar. Fonte: PDM Lisboa, 2013.

Em síntese, pode-se dizer que, de modo geral, as propostas de qualificação do solo contidas no PDM para essa área da cidade reforçariam a qualidade da base morfológica e contribuiriam para o cumprimento do Objetivo 2 - a promoção da reabilitação e da regeneração urbana.

\section{APLICAÇÃO AO PLANO DE PORMENOR DA MALHA 14 DO PLANO DE URBANIZAÇÃO DO ALTO DO LUMIAR}

Nos parágrafos seguintes, descreve-se a aplicação da Morpho a um caso de maior detalhe dentro da mesma área do Lumiar, que permite analisar os outros cinco critérios que estruturam essa técnica de análise morfológica. $O$ caso escolhido foi o Plano de Pormenor da Malha 14 (PP-M14) do Plano de Urbanização do Alto do Lumiar (PUAL), promovido pela Sociedade Gestora da Alta de Lisboa e desenhado pelos arquitetos Carlos Guimarães e Luís Soares Carneiro (figura 6).

A avaliação do primeiro critério da Morpho não sofre qualquer alteração referente às propostas do PDM, já que este não propõe a abertura de novas ruas, mas apenas o redesenho das existentes. Relativamente à densidade de parcelas, as propostas do plano conduzem à definição de cinco novas parcelas, o que naturalmente tem impacto extremamente reduzido sobre a média da cidade, mas, ainda assim, impacto quantificável e positivo. No que se refere à época de construção dos edifícios, o terceiro critério da Morpho, fica-se perante uma nova intervenção com a construção de cinco novos 


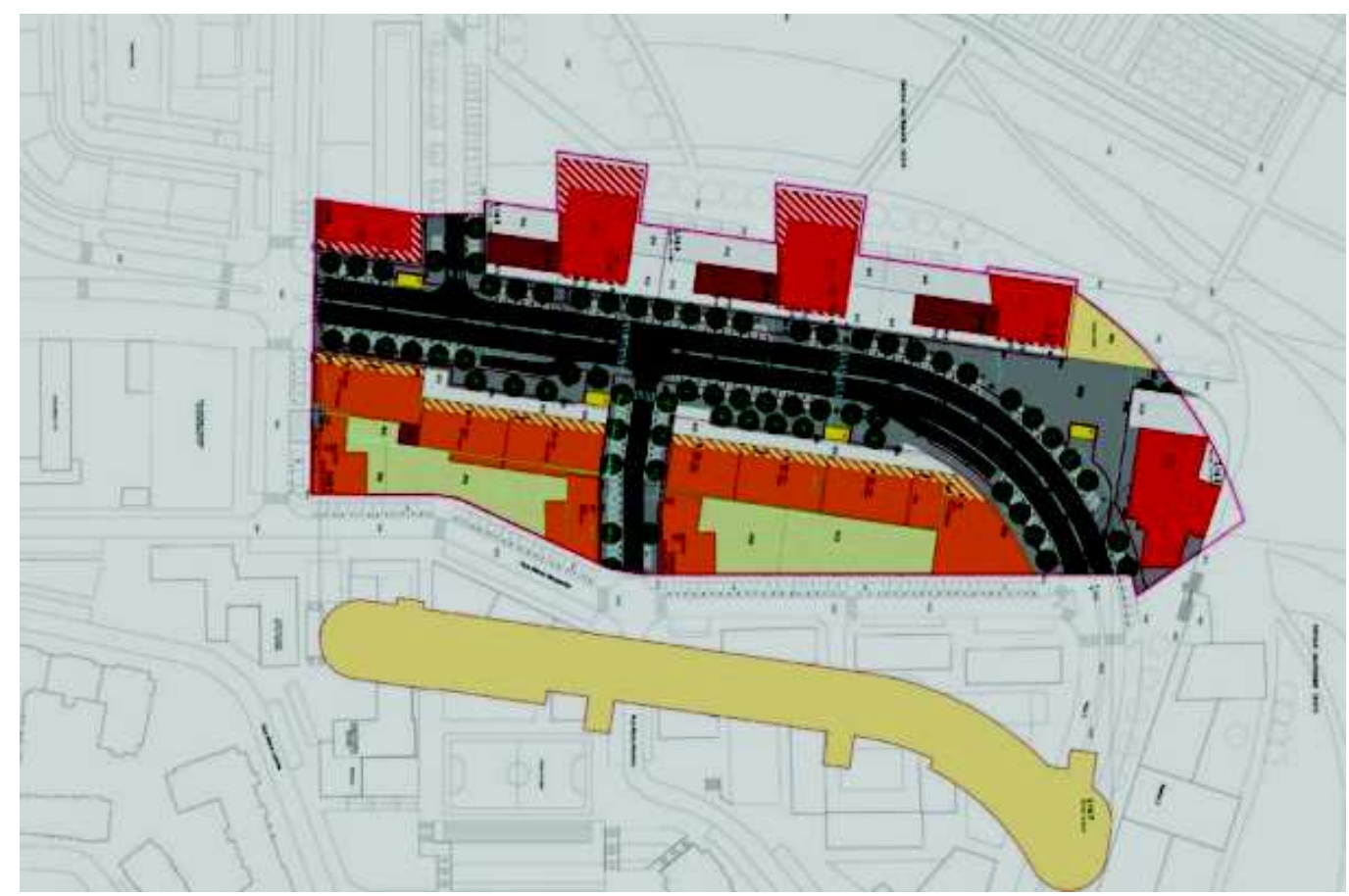

Figura 6 Plano de Pormenor da Malha 14.

Fonte: Plano de Pormenor da Malha 14, 2013.

edifícios, o que significa diminuição residual do índice.

À semelhança do critério 1, também em relação ao critério 4 não se regista qualquer alteração, já que não há abertura de novas ruas. Quanto ao alinhamento dos edifícios, o PP-M14 estabelece alinhamento do lado poente da rua, que em termos de extensão é maior do que o alinhamento preexistente no lado nascente. Isso significa que se passa de uma permanência de alinhamento em $50 \%$ da rua para uma permanência de alinhamento em $61 \%$ da rua. Quanto à relação entre altura dos edifícios e largura da rua, a construção desses cinco edifícios (com cérceas de 10 a 14 pisos) se traduz numa maior conformação da rua canal. Em termos numéricos, e olhando não para o impacto na cidade, mas sim para o impacto mais localizado, significa que esse rácio tem aumento substancial, passando de 0,2 para 0,64. Finalmente, com relação a funções, a proposta dos cinco edifícios (três com mistura funcional e dois apenas com função residencial) num quarteirão anteriormente sem nenhum terá naturalmente impactos positivos.

Concluindo, é possível dizer que a implementação do PP-M14 nessa área do Lumiar contribuiria para o reforço da qualidade da base morfológica da cidade (variação positiva em quatro dos sete critérios) e o cumprimento do Objetivo 2 do PDM de Lisboa. 
Vítor Oliveira

\section{REFERÊNCIAS BIBLIOGRÁFICAS}

CATALDI, G.; MAFFEI, G. L.; VACCARO, P. Saverio Muratori and the Italian school of planning typology. Urban Morphology. ISUF, 6, 2002, p. 3-14.

DUANY, Andrés. Introduction to the special issue: the transect. Journal of Urban Design, Taylor and Francis, 7, 2002, p. 251-60.

HILLIER, Bill. Space is the machine. Cambridge: Cambridge University Press, 1996.

. A theory of the city as object: or, how spatial laws mediate the social construction of space. Urban Design International, Springer, 7, 2002, p. 153-179.

; HANSON, Julliene. The social logic of space. Cambridge: Cambridge University Press, 1984.

HOLANDA, Frederico de. Arquitetura e urbanidade. Brasília: FRBH Edições, 2011.

KROPF, Karl. Urban tissue and the character of towns. Urban Design International, 1, 1996, p. 247-63.

LEES, L. Planning urbanity? Environment and Planning B, Sage, 42, p. 2.302-2.308.

MARCUS, Lars. Spatial capital: a PROPOSAL for an extension of space syntax into a more general urban morphology. Journal of Space Syntax, Space Syntax, 1, 2010, p. 30-40.

STAHLE, A.; MARCUS, L.; KARLSTROM, A. Place syntax-geographic accessibility with axial lines in GIS'. Estocolmo: School of Architecture, Royal Institute of Technology, 2006. Unpublished paper.

WHITEHAND, Jeremy W. R. Conzenian urban morphology and urban landscapes. In: INTERNATIONAL SPACE SYNTAX SYMPOSIUM, 6, 2007, Istanbul, Proceedings, Istanbul, 2007. Disponível em: <http://www.spacesyntaxistanbul.itu.edu.tr/>.

\section{AGRADECIMENTO}

Agradeço a Mafalda Silva pelo trabalho de implementação da morfologia Morpho em Lisboa. 